\title{
Challenges faced in managing dementia in Alzheimer's disease in patients with Down syndrome
}

This article was published in the following Dove Press journal:

Degenerative Neurological and Neuromuscular Disease

20 September 2016

Number of times this article has been viewed

\author{
Vee P Prasher \\ Hassan Mahmood \\ Madhumanti Mitra \\ Birmingham Learning Disability \\ Service, Birmingham Community \\ Healthcare NHS Foundation Trust, \\ Birmingham, UK
}

Correspondence: Vee P Prasher Birmingham Learning Disability Service, Birmingham Community Healthcare NHS Foundation Trust, The Greenfields, 30 Brookfield Road, Birmingham B30 3QY, UK

Tel +44 I2I 4663952

Email vprasher@compuserve.com

\begin{abstract}
Dementia in Alzheimer's disease (DAD) is more common in adults with Down syndrome (DS), with characteristically an earlier onset. The treatment of DAD is not too dissimilar in the general population and in people with intellectual disabilities. However, the underlying intellectual disability can make the management of DAD more challenging in older adults with DS. This literature review aimed to look at the management of DAD in people with DS. The management of dementia is holistic. This includes treating reversible factors, aiming to slow the cognitive decline, psychological therapies, ensuring that the environment is appropriate, and use of psychotropic medication when necessary to manage behavioral problems, psychotic symptoms, depressive symptoms, and sleep difficulty. Antidementia medications have a role to play but remain limited. The management of DAD in the DS population can be at times challenging, but good clinical practice should involve accurate diagnosis of dementia, treating any reversible additional factors, consideration of psychological and behavioral management, use of antidementia medication, and a multidisciplinary team approach.
\end{abstract}

Keywords: Down syndrome, Alzheimer's disease, dementia, management

\section{Introduction}

A trisomy of chromosome 21, Down syndrome (DS) is the commonest known cause of intellectual disabilities (ID). ${ }^{1}$ Although DS is usually apparent at birth, the associated clinical features of DS tend to become apparent after the first year of an individual's life, as reflected by delayed motor milestones, impaired communication, and generalized intellectual impairment. ${ }^{2}$ There is wide variation in intellectual ability, but the majority of people with DS have an IQ of $<50 .{ }^{1}$ A number of established physical and psychological disorders are associated with DS, such as congenital heart disease, thyroid disorders, sensory impairments, depression, autistic-type behaviors, and dementia. ${ }^{3}$ The life expectancy for the DS population has dramatically increased from a mean of 9 years in 1929 to a mean of 57-58 years today. ${ }^{4}$ As people with DS live longer, they are susceptible to a number of age-related disorders. For adults with DS, the most significantly associated illness is dementia of Alzheimer's disease (DAD). ${ }^{5,6}$ Virtually all adults aged 40 years and older have pathological brain changes of Alzheimer's disease (AD), ${ }^{7}$ but the onset of DAD is often some 10 years later. ${ }^{8}$ The clinical prevalence of DAD in people with DS has been reported to be $9 \%$ for age group 40-49 years, 36\% for age group 50-59 years, and 55\% for age group 60-69 years. ${ }^{9}$ The mean age of onset of DAD is 50-55 years. ${ }^{10}$ Most importantly, although DAD is very common, it is not inevitable in aging DS individuals. 
This review focuses on DAD as one specific form of dementia in the DS population. Other forms of dementia, such as vascular dementia, frontotemporal dementia, dementia with Lewy bodies, and mixed dementia, can occur in people with DS but are uncommon. ${ }^{11}$ By far, the commonest type of dementia is DAD, and the two main challenges faced by clinicians who care for older people with DS are: 1) the accurate diagnosis of DAD and 2) the subsequent treatment of DAD. This article reviews these areas of concern.

\section{Diagnosis of DAD in DS}

\section{Clinical presentation of DAD in DS}

In adults with DS, DAD usually presents with the same type of symptoms and signs as seen in the non-ID population. However, there may be a difference in presentation due to effects of underlying ID, comorbid illnesses, poor communication to elicit symptoms from the patient, and the increased reliance on informants. These factors can sometimes lead to a delay in diagnosis, misdiagnosis, and/ or delayed treatment. The clinical presentation of DAD often includes cognitive decline, loss of adaptive skills, behavioral problems, seizures, and physical symptoms. ${ }^{12,13}$ However, other symptoms, including mood changes, sleep disturbance, dysphagia and weight loss, daytime wandering, apathy, gait deterioration, hallucinations, sphincter incontinence, and presence of pathological release reflexes, can also occur. ${ }^{12,13}$ An individual affected with DS may initially present with short-term memory loss, but over the next 4-7 years he/she may present with the more typical features of DAD, finally becoming bedridden, requiring total nursing care. ${ }^{12,13}$

\section{Diagnosis of DAD in DS}

The National Task Group on Intellectual Disabilities and Dementia Practices ${ }^{14}$ recommends using at least one standardized tool for cognitive assessment and longitudinal assessments, giving more valuable information than a crosssectional assessment. A change in symptom over time is usually seen as being significant.

Regarding the initial assessment, this can be at the patient's home or within the hospital setting. Interviewing patients in their own home environment is likely to be less stressful for the patient and ensures that the individual is seen. Usually, a comprehensive history from family members and carers can also be taken at that time. The hospital setting may be in Memory Clinics, which are well established in the non-ID population and are now being developed for the ID population. These specialist clinics usually benefit from the expertise of a multidisciplinary team who are able to do a joint assessment. Basic investigations such as blood tests, electrocardiogram, and electroencephalogram (EEG), may be undertaken. A separate multidisciplinary team meeting subsequently is often needed to collate all information and consider the diagnosis of DAD.

Often, the key information to ascertain during the initial assessment is whether there has been a decline in intellectual or/and adaptive skills. As this can be problematic, it has been suggested that routine cognitive and adaptive assessments should be done on all adults with DS between 30 years and 40 years, repeated at regular intervals between 40 years and 50 years. This would eventually help in a diagnosis of dementia, as a change in functioning will be much easier to detect. There is, however, no published research to date demonstrating the benefits of such an approach.

The next step in the assessment of DAD is to ascertain the reason for the intellectual and/or adaptive decline. Are we seeing age-associated decline (normal aging) or signs of an underlying disorder? At this stage, it is important to rule out possible causes of cognitive decline, including physical health problems, sensory impairments, psychiatric comorbidity, effects of medication, and environmental causes. This can be done in a systematic way as follows:

- clinical history,

- mental state examination (MSE),

- physical examinations,

- blood laboratory investigations,

- EEG/brain neuroimaging,

- brief neuropsychological assessments.

A clinical history taken from patient and carers and additional information obtained from patient records should ascertain which symptoms of dementia are present if any (as discussed earlier). In addition, it would be important to know about the presence of any psychiatric symptoms currently, past psychiatric history, past medical history, including cardiovascular risk factors, family history, any recent life events, and medication history. MSE should be done as per the non-ID population, with particular focus on the level of alertness, fluctuations in consciousness, psychomotor agitation/retardation, presence of psychotic symptoms, rapport, and cognitive functioning. Due to the underlying ID and limited communication, the MSE may require involvement of carers. A physical examination should be done wherever possible, although the lack of patient cooperation may limit the examination. Particular focus should be given to vision and hearing, weight, any extra pyramidal signs, and hypothyroidism signs. 
In terms of examinations, routine blood tests should be carried out, including complete blood count, B12, folate, urea and electrolytes, blood sugar, liver function tests, lipid profile, and thyroid function tests. Some centers now request apolipoprotein E (APOE) status. APOE e4 allele significantly increases the risk of DAD, whereas APOE e2 is protective and reduces risk. Although an EEG and CT/MRI brain imaging can be useful in differentiating dementia from delirium and detecting seizure disorders or a space occupying lesion, their role is limited.

Although there is no internationally agreed single neuropsychological test battery for DAD in DS, a number of bedside tests are widely available, which include 1) Dementia Questionnaire for People with Intellectual Disabilities, 2) Dementia Scale for Downs Syndrome, 3) Dementia Screening Questionnaire in Intellectual Disability, and 4) Adaptive Behavior Dementia Questionnaire. The CAMDEX-DS can be used for a detailed assessment of orientation, language, memory, attention, praxis, abstract thinking, and perception. An assessment of daily living skills can be done using AAMD Adaptive Behavior Scale or the Vineland Adaptive Behavior Scale.

Once all information, including investigatory results, is made available, the information should be reviewed to see if it fulfils recognized diagnostic criteria for DAD. The following two internationally recognized systems are available: tenth revision of the International classification of Diseases ${ }^{15}$ and the Diagnostic and Statistical Manual of Mental Disorders - fifth edition (Table 1). ${ }^{16}$ Such diagnostic criteria are limited in their validity to detect DAD in the ID population, but nevertheless, they do have an important role to play in the diagnosis of DAD in people with DS.

\section{Differential Diagnoses for DAD in DS}

There are, of course, many causes of cognitive deterioration in people with DS (Table 2). The common differential diagnoses for DAD are hypothyroidism, depression, and

Table I Overview of standardized criteria for dementia in Alzheimer's disease according to the ICD-10 and DSM-V

Gradual decline in memory affecting daily function for $>6$ months not due to other physical or psychological causes

Decline in higher order functions, including language, praxis, perception, and executive function

Decline in adaptive daily living skills

No fluctuation in consciousness

Some changes in emotions, social functioning, and personality

Abbreviations: ICD-10, International Classification of Diseases - tenth revision DSM-V, Diagnostic and Statistical Manual of Mental Disorders - fifth edition.
Table 2 Common causes of cognitive deterioration in adults with DS

\begin{tabular}{ll}
\hline $\begin{array}{l}\text { Sensory } \\
\text { impairments }\end{array}$ & Vision loss and hearing loss \\
$\begin{array}{l}\text { Metabolic } \\
\text { disorders }\end{array}$ & $\begin{array}{l}\text { Thyroid dysfunction, BI2/folate deficiency, and anemia } \\
\text { Hypo/hyperglycemia and electrolyte abnormalities }\end{array}$ \\
Mental ill-health & Depression and paranoid states \\
Medication & Side effects of drugs and interactions \\
Psychosocial & Bereavement, changes in environment, and loss \\
Sleep problems & Sleep apnea \\
Seizures and & Epilepsy, long-term effects of anticonvulsants, and \\
related issues & head injuries \\
Neurological & Cervical spine compression by atlantoaxial instability \\
\hline
\end{tabular}

Abbreviation: DS, Down syndrome.

adverse effects of medication. It should be possible that once a full and detailed assessment for DAD has been done, a number of possible differential causes of intellectual decline can be excluded.

\section{Treatment of DAD}

Management of DAD involves the multidisciplinary team. This includes the psychiatrist who can look at medications, nurse specialist who may or may not prescribe, psychologist to conduct cognitive assessments, and a number of other professionals, such as occupational therapist, speech and language therapist, physiotherapist, and pharmacist. A number of Memory Clinics have now been established that facilitate the management process. The treatment of DAD involves pharmacological and nonpharmacological treatments. The former may use drugs to treat the underlying $\mathrm{AD}$ process or drugs to treat the symptoms of DAD.

\section{Drug treatment of $A D$}

As compared to the non-ID population, data from research studies investigating the efficacy of drug treatment for $\mathrm{AD}$ are scarce, and even those are limited by a number of methodological issues, small sample sizes, nonblinded studies, poor diagnostic accuracy for DAD, validity of test instruments, and limited follow-up of samples. To date, several drugs have been approved that either increase availability of acetylcholine (donepezil, rivastigmine, and galantamine) or block the role of the neurotransmitter glutamate (memantine) (Tables 3-5).

Prasher et $\mathrm{al}^{17}$ carried out a 24 -week double-blind, placebo-controlled trial of donepezil in patients with DS and DAD. The study set out to investigate the safety and efficacy of donepezil in adults with DS with mild-moderate DAD. The researchers found no statistically significant reduction in deterioration in the assessment of DAD as compared to 
Table 3 Antidementia drugs and their profile

\begin{tabular}{|c|c|c|c|c|c|c|c|c|}
\hline Medication & $\begin{array}{l}\text { Chemical } \\
\text { class }\end{array}$ & Action & $\begin{array}{l}\text { Type of } \\
\text { inhibition }\end{array}$ & $\begin{array}{l}\text { Route of } \\
\text { administration }\end{array}$ & $\begin{array}{l}\text { Frequency of } \\
\text { administration }\end{array}$ & $\begin{array}{l}\text { Given } \\
\text { with food? }\end{array}$ & $\begin{array}{l}\text { Dosage per } \\
\text { day }(\mathrm{mg})\end{array}$ & Indications \\
\hline Donepezil & Piperidine & $\begin{array}{l}\text { AChE } \\
\text { inhibitor }\end{array}$ & $\begin{array}{l}\text { Rapidly } \\
\text { reversible }\end{array}$ & Oral tablets & Once a day & No & $5-10$ & $\begin{array}{l}\text { Mild-moderate } \\
A D\end{array}$ \\
\hline Rivastigmine & Carbamate & $\begin{array}{l}\mathrm{AChE} \\
\text { and } \mathrm{BChE} \\
\text { inhibitors }\end{array}$ & $\begin{array}{l}\text { Pseudo- } \\
\text { reversible }\end{array}$ & $\begin{array}{l}\text { Oral capsules, } \\
\text { oral solution, } \\
\text { and patches }\end{array}$ & Twice a day & Yes & $6-12$ & $\begin{array}{l}\text { Mild-moderate } \\
\text { AD }\end{array}$ \\
\hline Galantamine & $\begin{array}{l}\text { Phenanthrene } \\
\text { alkaloid }\end{array}$ & $\begin{array}{l}\text { AChE } \\
\text { inhibitor }\end{array}$ & $\begin{array}{l}\text { Rapidly } \\
\text { reversible }\end{array}$ & Oral tablets & Twice a day & Yes & $16-24$ & $\begin{array}{l}\text { Mild-moderately } \\
\text { severe AD }\end{array}$ \\
\hline Memantine & $\begin{array}{l}\text { Glutaminergic } \\
\text { modulator }\end{array}$ & $\begin{array}{l}\text { NMDA } \\
\text { antagonist }\end{array}$ & $N / A$ & $\begin{array}{l}\text { Oral tablets and } \\
\text { oral solution }\end{array}$ & Twice a day & No & $10-20$ & $\begin{array}{l}\text { Moderately } \\
\text { severe-severe AD }\end{array}$ \\
\hline
\end{tabular}

Note: Copyright @20I3 Radcliffe Press. Adapted with permission from Prasher VP. Alzheimer's Disease, Dementia, Down syndrome and Intellectual Disabilities. UK: Radcliffe Press; 2005."

Abbreviation: AD, Alzheimer's disease; AchE, acetylcholinesterase; BChE, butyrylcholinesterase; NMDA, N-Methyl-D-aspartate; N/A, not applicable.

Table 4 Commonly occurring side effects of the antidementia drugs

\begin{tabular}{|c|c|c|c|c|}
\hline Adverse event & Donepezil & Rivastigmine & Galantamine & Memantine \\
\hline Nausea & + & + & + & \\
\hline Diarrhea & + & + & + & + \\
\hline Insomnia & + & + & + & + \\
\hline Fatigue & + & + & + & + \\
\hline Vomiting & + & + & + & + \\
\hline Muscle cramps & + & & & \\
\hline Anorexia & + & + & + & \\
\hline Headache & + & + & + & + \\
\hline Dizziness & + & + & + & + \\
\hline Syncope & + & + & + & \\
\hline Urinary incontinence & + & & & \\
\hline Psychiatric disturbances & + & + & + & + \\
\hline Rash & + & + & + & \\
\hline Pruritus & + & & & \\
\hline Weight loss & & + & + & \\
\hline Abdominal pain & & + & & \\
\hline Drowsiness & & + & & \\
\hline Hallucinations & & & & + \\
\hline Cardiac changes & + & & + & + \\
\hline Cystitis & & & + & + \\
\hline Increased libido & & & + & \\
\hline
\end{tabular}

Note: Copyright @2013 Radcliffe Press. Adapted with permission from Prasher VP. Alzheimer's Disease, Dementia, Down syndrome and Intellectual Disabilities. UK: Radcliffe Press; 2005."

Table 5 Conditions where antidementia therapy should be used with caution

\begin{tabular}{ll}
\hline Drug & Condition \\
\hline Donepezil & $\begin{array}{l}\text { Sick sinus syndrome, supraventricular conduction } \\
\text { abnormalities, history of peptic ulcers, asthma, chronic } \\
\text { obstructive airway disease, and hepatic impairment } \\
\text { Rivastigmine }\end{array}$ \\
$\begin{array}{l}\text { Renal impairment, hepatic impairment, sick sinus syndrome, } \\
\text { supraventricular conduction abnormalities, history of peptic } \\
\text { ulcers, asthma, and chronic obstructive airway disease }\end{array}$ \\
Galantamine & $\begin{array}{l}\text { Sick sinus syndrome, supraventricular conduction } \\
\text { abnormalities, history of peptic ulcers, asthma, chronic } \\
\text { obstructive airway disease, hepatic impairment, and } \\
\text { urinary obstruction }\end{array}$ \\
Memantine & $\begin{array}{l}\text { Renal impairment, caution in patients with epilepsy, and } \\
\text { cardiovascular disorders }\end{array}$ \\
\hline
\end{tabular}

Note: Copyright (C) 2013 Radcliffe Press. Adapted with permission from Prasher VP. Alzheimer's Disease, Dementia, Down syndrome and Intellectual Disabilities. UK: Radcliffe Press; 2005."' the placebo group. The medication was found to be safe in this vulnerable group.

Lott et $\mathrm{al}^{18}$ also reported on the efficacy of donepezil in adults with DS. The sample consisted of six treated patients with DS and nine matched historical controls. Donepezil was administered for 5 months. Results showed significant improvement in dementia scores for the treated group. Along with other studies, ${ }^{19-21}$ there was a consensus of medical opinion that donepezil may be efficacious in slowing down the rate of dementia in the DS population.

Nonsignificant improvement in cognitive and adaptive functioning with the use of oral or transdermal rivastigmine over a 6-month period had been demonstrated by Prasher et al. ${ }^{22,23}$ Although in clinical practice galantamine has been 
used to treat DAD in people with DS, to date no research information has been published.

Hanney et $\mathrm{al}^{24}$ undertook a prospective randomized double-blind trial of memantine in the DS population. The study enrolled adults ( $>40$ years) with karyotypic or clinically diagnosed DS, with and without dementia, at four ID centers in the UK and Norway. Subjects were randomly allocated to receive memantine $(\mathrm{N}=88)$ or placebo $(\mathrm{N}=85)$ for 52 weeks by use of a computer-generated sequence. The primary outcome was change in cognition and function, measured with DAMES scores and the adaptive behavior scale parts I and II. Both groups declined in cognition and function, but rates did not differ between groups for any outcomes. Ten participants in the memantine group and six participants of controls had serious adverse events. Five participants in the memantine group and four participants of controls died from serious adverse events.

In $2009^{25-28}$ and $2015,^{29}$ the Cochrane Collaboration conducted reviews to assess the effectiveness of antidementia medications and nutritional supplements for the treatment of cognitive decline in people with DS. Selection criteria were as follows: randomized controlled trials of antidementia medications and nutritional supplements for adults with DS, in which treatment was administered and compared with either placebo or no treatment. In the 2009 Cochrane reviews, ${ }^{25-28}$ only one study met the strict criteria for antidementia drug trials ${ }^{17}$ and at best, only a modest trend in favor of the use of donepezil was found. By 2015, nine studies were found that examined the effects of drugs on cognition in the DS population. ${ }^{25-28}$ The only medicine to show any positive effect was simvastatin. ${ }^{30}$ Overall, due to lack of rigorous research information, the 2009 and 2015 Cochrane Collaboration reviews of donepezil, galantamine, rivastigmine, and memantine could not recommend their use to treat DAD in the DS population. The overall quality of the evidence was low and most trials involved small numbers of participants. Furthermore, larger randomized controlled trails with longer follow-up were needed.

National Institute of Health and Care Excellence (NICE) guidance (2006, updated April 2015) ${ }^{31}$ recommended the use of acetylcholinesterase inhibitors for mild-to-moderate $\mathrm{AD}$ to delay the progress of the illness. Memantine can be used in those with moderate $\mathrm{AD}$ who are intolerant of or have a contraindication to acetylcholinesterase inhibitors or in those with severe AD. However, NICE guidance ${ }^{31}$ has restated that difficulty in staging dementia in people with ID should not disadvantage them. As a result, some flexibility has been introduced for prescribers.
Overall, there is no conclusive evidence that these medications are effective in slowing the cognitive decline in people with ID. However, available evidence suggests that these medications could improve the quality of life of both the patients and their carers.

A number of other medication regimes have been proposed following research trials in the non-ID population, which include Ginkgo biloba, ${ }^{32}$ antioxidant supplementation, ${ }^{33}$ and NSAIDs. ${ }^{34}$ To date, research evidence appears to be uncertain regarding their efficacy. No research trials in the DS population have been undertaken, and therefore, their use in the DS population has not been recommended.

\section{Behavioral problems and antipsychotics}

Most people with DS and DAD who have behavioral problems, such as aggression, anxiety, agitation, mood changes, and irritability, can be managed with environmental and other psychosocial approaches..$^{35}$ Education to caregivers, training in behavioral management, and ongoing professional support can be effective in alleviating the burden on carers and reduce the need for pharmacological interventions. Where psychotropic medications are used, the target symptoms should be clearly recorded. Risks and benefits of the medications should be discussed with the individual and/ or carers. The minimum effective dose should be used for the shortest duration. The use of psychotropic medications to control behavior problems in dementia should only be considered as a last resort or where there is clear evidence of psychotic symptoms, such as delusions, hallucinations, and paranoia.

NICE guidelines on dementia ${ }^{36}$ state that those with severe noncognitive symptoms (psychosis and/or agitated behavior causing significant distress) may be offered treatment with an antipsychotic drug after meeting the following conditions:

- There should be a full discussion with the individual with dementia and/or carers about possible benefits and risks of treatment. There should be an assessment of cerebrovascular risk factors and a discussion surrounding the risk of stroke or TIA and possible adverse effects on cognition.

- Cognitive changes should be assessed and recorded regularly. If necessary, alternative medication should be considered.

- Target symptoms should be identified, quantified, and documented.

- There should be a regular assessment and recording of any changes in target symptoms. 
- There should be a consideration of the effect of any comorbid conditions, such as physical illness, pain, and depression.

- After an individual risk-benefit analysis, the choice of antipsychotic should be made.

- The initial dose of medication should be low and then titrated upward.

- The treatment should be time-limited and reviewed on a regular basis, eg, every 3 months or according to clinical need.

A wide range of old and new antipsychotic drugs are available (Table 6), and their role in the treatment of dementia has been reviewed. ${ }^{37}$ The majority of antipsychotic drugs interfere with dopaminergic transmission in the brain by blocking dopamine $\mathrm{D} 2$ receptors.

Practitioners should ensure good practice when prescribing antipsychotics to an individual with DS and DAD. Good practice includes: prescribing only one antipsychotic drug; using the lowest effective dose possible; only using higher doses with caution and with close supervision; avoiding multipsychotic pharmacy; limiting the usage of anticholinergic drugs to reduce side effects of antipsychotic medication; monitoring the response to medication regularly.

There is limited research information on the use of antipsychotic medication in people with DS and DAD. Findings from the non-ID population suggest that any benefit seen may not be dose related and may be temporary. Withdrawal of drugs should always be gradual to avoid acute withdrawal syndromes or reoccurrence of symptoms. Side effects are common but may not be easily identified (Table 7).

\section{Depression and use of antidepressants}

People with DS are more likely than non-ID people to experience other comorbidities, including mental health issues, such as depression. ${ }^{38}$ Depression can present as dementia or can occur as part of a dementing illness. Wark et $\mathrm{al}^{39}$ reported

Table 6 Common neuroleptic drugs

\begin{tabular}{ll}
\hline Conventional & Atypical \\
\hline Haloperidol & Amisulpride \\
Chlorpromazine & Risperidone \\
Trifluoperazine & Olanzapine \\
Flupenthixol & Quetiapine \\
Promazine & Aripiprazole \\
Pimozide & Clozapine \\
Fluphenazine & Zotepine \\
Benperidol & Sertrindole \\
& Ziprasidone \\
\hline
\end{tabular}

Table 7 Side effects of antipsychotics

\section{Sedation}

Hyperprolactinemia

Reduced seizure threshold

Postural hypotension

Anticholinergic side effects (dry mouth, blurred vision, urinary problem, and constipation)

Neuroleptic malignant syndrome

Weight gain

Extrapyramidal-dystonic reactions

Pseudoparkinsonism (bradykinesia, rigidity, and tremor)

Akathisia (restlessness of the hand, finger, and foot movement)

Tardive dyskinesia (repetitive and involuntary movements)

a study where three people with DS and dementia were described as experiencing a "rebound" in functioning after a clear and sustained period of decline. It was felt that rather than a reversal of the expected dementia process, there was an undiagnosed depression that exaggerated the real level of functional decline associated with the dementia. It has been reported $^{40,41}$ that the quality of life of some patients with DS and DAD can be improved and longevity increased by the identification and treatment of depressive symptoms.

There are several types of antidepressants that can be prescribed: 1) tricyclic antidepressants (eg, amitripytline, lofepramine, and dothiepin); 2) monoamine oxidase inhibitors (eg, phenelzine); 3) selective serotonin reuptake inhibitors (SSRIs; eg, fluoxetine, fluvoxamine, paroxetine, and sertraline); 4) noradrenergic and specific serotonergic antidepressants (eg, mirtazapine); 5) selective noradrenaline reuptake inhibitors (eg, reboxetine); 6) serotonin/noradrenaline reuptake inhibitors (eg, venlafaxine).

For people with DAD and depression and more so than for the general population, the rational use of antidepressants is dependent on the awareness of their side effects, drug interactions, and secondary complications. Tricyclic medication, eg, should be used with caution as the risk of experiencing detrimental side effects is high. The SSRIs are thought to be as efficacious as the older forms of antidepressants, but the side effect profile (less sedation, less cardiotoxicity, and less anticholinergic side effects) is more benign and the risk from overdose is much lower. SSRIs may have greater efficacy in people with aggressive behavior. If there is no little or no benefit with a 5-8-week course of an antidepressant, the diagnosis should be reviewed. Discontinuation reactions (withdrawal symptoms) have been reported for virtually all classes of antidepressants. Reactions start 2-3 days after stopping the antidepressant, but most are mild and short lived. Common symptoms include dizziness, nausea, headache, lethargy, sleep disturbance, agitation, and restlessness. The 
likelihood of a discontinuation reaction can be prevented by gradual reduction of the antidepressant over 4-6 weeks.

Rapid mood swings are often observed in older people with DS and dementia. ${ }^{10}$ Mood stabilizers, such as lithium, sodium valproate, and carbamazepine, can be subsequently prescribed. Lithium, however, should be used with caution in the elderly DS population because of its limited therapeutic range, high risk of interaction with other drugs (eg, diuretics), and high risk of lithium toxicity. Lithium toxicity is life threatening and occurs when blood lithium levels are significantly raised above acceptable limits. Lithium toxicity can present with various symptoms, including apathy, being sluggish, tremor, twitching, muscle weakness, ataxia, difficulties in speech, vomiting, diarrhea, and nausea. Lithium toxicity is a medical emergency that requires medical health attention immediately.

Semisodium valproate (Depakote) and carbamazepine can be prescribed to stabilize mood swings. However, due to adverse effects and drug interactions, their use is limited in people with DS and dementia.

\section{Insomnia and hypnotics}

A disturbed sleep pattern is a common symptom of DAD in people with DS. Difficulties in falling asleep, wakening at early hours, and sleeping during the day but awake at night are common complaints made by carers. A detailed assessment of the sleep, including the pattern, duration, and severity of disturbed sleep, should be documented. A physical examination and review of medication should rule out any pain, urinary incontinence, and side effects of medication as causes of poor sleep. This should always be done before assuming the cause is dementia.

Nonpharmacological treatments may benefit the sleep pattern by encouraging maintenance of good sleep hygiene. These include limiting the stimulant use in the evening, maintaining a regular sleep routine, minimizing excessive noise, ensuring that the patient is not disturbed when dispensing medication, encouraging toilet use before going to bed, avoiding daytime sleeping, and ensuring an appropriate temperature in the room. ${ }^{42}$

As a last resort, night sedative medication may be prescribed. The initial prescribed dose should be as low as possible, for a short duration, reviewed after a few days and increased in dose only when needed. Possible interactions with other medications (eg, antidementia drugs and antipsychotics) should be observed. The commonest types of hypnotics used include nitrazepam, temazepam, lorazepam, chloral hydrate, melatonin, zopiclone, zaleplon, and zolpidem.
Benzodiazepines and Z-drugs are the commonest type of drugs prescribed for insomnia. They work by increasing neuronal inhibition by gamma-aminobuytric acid. All hypnotics have a rapid onset of action, but tolerance can develop after a few weeks. Cessation of any hypnotic should be done slowly as abrupt cessation can lead to rebound insomnia. Long-term use should be avoided as a number of adverse effects are associated with hypnotic drug use. Oversedation and daytime hangover effects can further impair cognitive function. Unsteadiness, falls, confusion, and apathy are also common side effects.

\section{Seizures and antiepileptic medication}

During the past two decades, an association between seizures and dementia in adults with DS has been established. ${ }^{43-45}$ Late-onset seizures are a strong indicator of an underlying dementing process and are a poor prognostic factor. ${ }^{46}$ Prasher and Corbett ${ }^{46}$ found that the mean life expectancy after the onset of seizures in people with DS and DAD was only 1.5 years.

Drug treatment is dependent on the type of epilepsy or seizures. The object of treatment is to reduce or stop seizures occurring with an effective dose of one or more antiepileptic drugs. The medication should be started at a low dose. There should be careful adjustment, with a gradual increase in dose medication until seizures reduce or adverse effects occur. Monotherapy with a first-line drug and again with a second-line drug should be tried before combination therapy is started. Sodium valproate is the first-line treatment for generalized tonic-clonic seizures. Lamotrigine can be used as an alternative to sodium valproate. Carbamazepine can be used. For absence seizures, ethosuximide and sodium valproate are the drugs of choice; lamotrigine can be used as an alternative. For myoclonic seizures, sodium valproate is the drug of choice, with topiramate and levetiracetam being the alternatives. Focal seizures are uncommon in dementia, but carbamazepine and lamotrigine are the first-line options.

Antiepileptic medication can induce cognitive deficits. ${ }^{47}$ Regarding the use of other medications in people with DS and DAD, caution in terms of dosage should be taken and regular reviews of medication should be carried out.

\section{Nonpharmacological interventions}

Psychological interventions need to consider multiple areas of behavior in an individual with DS and DAD. These include behavior, emotion, cognition, and stimulation. A multidimensional approach ensures better support for the individual. It enables the carers to cope, understand, and manage the 
behavior and emotional distress associated with DAD. ${ }^{48}$ This type of approach ensures that there is a responsibility placed on the "system of care" to change and communicate effectively with the affected people while enhancing their present capabilities.

In all cases of challenging behavior that is seen in an individual with DAD, a full psychological assessment of the behavior, its predisposing factors, and subsequent responses should occur. A psychological or behavioral intervention should address the individual, the environment, and the interaction between the two. Positive behavioral support is often the preferred treatment when patients present with challenging behaviors.

According to Marshall, ${ }^{49}$ the environmental design for patients with dementia should not hinder an individual. They should have beneficial effects for the individual and the staff. Examples of how an environment should have beneficial effects include the following: compensating for the disability; maximizing independence; enhancing self-esteem and confidence; demonstrating care for staff; being orientating and understandable; reinforcing personal identity; welcoming relatives and the local community; allowing control of stimuli.

For people with dementia, the environments need to be calm, predictable and make sense, familiar, suitably stimulating, and safe and risk assessed.

Carers experience considerable stress while looking after an individual with DAD. ${ }^{11}$ A number of carer interventions are available. These include education, emotional support, changes to the home environment, consideration of finances, and easy access to services. Education includes providing the carer with a wide breadth of information. This includes information about the diagnosis, disease, outcome, resources available, and treatment. Emotional support includes joining support groups locally, support from a community nurse, respite and day care, and individual psychological counseling. Adaptations to the home can help with bathing, self-care, and mobility. Structural changes to the home can reduce carer stress, in terms of safety adaptations. ${ }^{11}$

\section{Conclusion}

Research evidence has shown that individuals with DS are more susceptible than the general population to the development of DAD, and virtually all DS adults older than 40 years have the neuropathology of AD. DAD develops at a much earlier age. The management is holistic and should involve several caring disciplines. A differential diagnosis of DAD needs to be made from the normal aging process and from treatable causes of dementia. It is important to remember that physical illnesses can cause intellectual decline and challenging behavior; therefore, physical examination and physical investigations should be conducted when required. Once a diagnosis of DAD has been made, the multidisciplinary team will manage cognitive decline, comorbid mental health illness, seizures, behavioral challenges, and the environment, and monitor the use of psychological therapies and, if needed, find more appropriate accommodation.

As far as antidementia drugs are concerned for patients with DS and DAD, the evidence suggests that the medications have a limited role in terms of slowing down cognitive decline, as in patients who have DAD in the general population. Other medications, such as antipsychotics, antidepressants, anticonvulsants, and night sedation, can be prescribed by a medical practitioner. These drugs can improve the quality of life of patients with DS and DAD.

The management of DAD in people with DS does present with a number of challenges. However, if clinicians follow good clinical practice guidelines, optimum care can be provided to these under-resourced members of the community. Future research findings from the general population should be applicable to the DS population and will hopefully improve future management and diminish any challenges.

\section{Disclosure}

The authors report no conflicts of interest in this work.

\section{References}

1. Fryers T, Russell O. Applied epidemiology. In: Fraser W, Kerr M, editors. Seminars in the Psychiatry of Learning Disabilities. 2nd ed. London: The Royal College of Psychiatrits; 2003:16-48.

2. Semple D, Smyth R, editors. Oxford Handbook of Psychiatry. 3rd ed. Oxford: Oxford University Press; 2013.

3. Prasher VP, Prasher A. The Essential Guide to Healthcare for Adults with Down syndrome. Birmingham: BILD Publications; 2014.

4. Oliver C, Holland T. Down's syndrome and Alzheimer's disease: a review. Psychol Med. 1986;16(2):307-322.

5. Prasher VP, Sachdeva N, Tarrant N. Diagnosing dementia in adults with Down's syndrome. Neurodegener Dis Manag. 2015;5(3):249-256.

6. Holland AJ, Hon J, Huppert FA, Stevens F. Incidence and course of dementia in people with Down's syndrome: findings from a populationbased study. J Intellect Disabil Res. 2000;44(Pt 2):138-146.

7. Mann DM. The pathological association of Down syndrome and Alzheimer disease. Mech Ageing Dev. 1988;43(2):99-136.

8. Prasher VP. Temporal relationship between clinical and neuropathological dementia in people with Down syndrome. Br J Clin Soc Psychiatry. 1994;9:24-25.

9. Dalton AJ, Crapper-McLachlan DR. Clinical expression of Alzheimer's disease in Down's syndrome. Psychiatr Clin North Am. 1986;9: 659-670.

10. Prasher VP. Age-specific prevalence, thyroid dysfunction and depressive symptomatology in adults with Down syndrome and dementia. Int $J$ Geriatr Psychiatry. 1995;10(1):25-31.

11. Prasher VP. Alzheimer's Disease, Dementia, Down syndrome and Intellectual Disabilities. UK: Radcliffe Press; 2005. 
12. Evenhuis HM. The natural history of dementia in Down's syndrome. Arch Neurol. 1990;47(3):263-267.

13. Lai F, Williams RS. A prospective study of Alzheimer Disease in Down syndrome. Arch Neurol. 1989;46(8):849-853.

14. Moran JA, Rafii MS, Keller SM, et al; Rehabilitation Research and Training Center on Aging With Developmental Disabilities, University of Illinois at Chicago, American Association on Intellectual and Developmental Disabilities. The national task group on intellectual disabilities and dementia practices consensus recommendations for the evaluation and management of dementia in adults with intellectual disabilities. Mayo Clin Proc. 2013;88(8):831-840.

15. World Health Organization. The ICD-10 Classification of Mental and Behavioural Disorders: Clinical Descriptions and Diagnostic Guidelines. Geneva: World Health Organization; 1992.

16. American Psychiatric Association. Diagnostic and Statistical Manual of Mental Disorders. 5th ed. Washington, DC: American Psychiatric Association; 2013.

17. Prasher VP, Huxley A, Haque S; Down syndrome Ageing Study Group. A 24-week double blind, placebo-controlled trial of donepezil in patients with Down syndrome and Alzheimer's disease- pilot study. Int J Geriatr Psychiatry. 2002;17(3):270-278.

18. Lott IT, Osann K, Doran E, Nelson L. Down syndrome and Alzheimer disease: response to donepezil. Arch Neurol. 2002;59(7): 1133-1136.

19. Kishnani PS, Sullivan JA, Walter BK, Spiridigliozzi GA, Doraiswamy PM, Krishnan KR. Cholinergic therapy for Down's syndrome. Lancet. 1999;353(9158):1064-1065.

20. Heller JH, Spiridigliozzi GA, Sullivan JA, Doraiswamy PM, Krishnan RR, Kishnani PS. Donepezil for the treatment of language deficits in adults with Down syndrome: a preliminary 24-week open trial. Am J Med Genet A. 2003;116A(2):111-116.

21. Johnson N, Fahey C, Chicoine B, Chong G, Gitelman D. Effects of donepezil on cognitive functioning in Down syndrome. Am J Ment Retard. 2003;108(6):367-372.

22. Prasher VP, Fung N, Adams C. Rivastigmine in the treatment of dementia in Alzheimer's disease in adults with Down syndrome. Int $J$ Geriatr Psychiatry. 2005;20(5):496-497.

23. Prasher VP, Sachdeva N, Adams C, Haque MS. Rivastigmine transdermal patches in the treatment of dementia in Alzheimer's disease in adults with Down syndrome - pilot study. Int J Geriatr Psychiatry. 2013;28(2):219-220.

24. Hanney M, Prasher V, Williams N, et al; MEADOWS trial researchers. Memantine for dementia in adults older than 40 years with Down's syndrome (MEADOWS): a randomised, double-blind, placebo-controlled trial. Lancet. 2012;379(9815):528-536.

25. Mohan M, Bennett C, Carpenter PK. Memantine for dementia in people with Down syndrome. Cochrane Database Syst Rev. 2009;(1):CD007657.

26. Mohan M, Bennett C, Carpenter PK. Galantamine for dementia in people with Down syndrome. Cochrane Database Syst Rev. 2009;(1):CD007656.

27. Mohan M, Bennett C, Carpenter PK. Rivastigmine for dementia in people with Down syndrome. Cochrane Database Syst Rev. 2009;(1):CD007658.

28. Mohan M, Carpenter PK, Bennett C. Donepezil for dementia in people with Down syndrome. Cochrane Database Syst Rev. 2009;(1):CD007178.

29. Livingstone N, Hanratty J, McShane R, Macdonald G. Medications for cognitive decline in people with Down syndrome. Cochrane Database Syst Rev. 2015;(10):CD011546.
30. Cooper SA, Caslake M, Evans J, et al. Toward onset prevention of cognitive decline in adults with Down syndrome (the TOP-COG study): study protocol for a randomised controlled trial. Trials. 2014;15:202.

31. National Institute of Health and Care Excellence [webpage on the Internet]. Dementia: Supporting People with Dementia and Their Carers in Health and Social Care. Clinical Guidelines. 2006. CG42. Available from: www.nice.org.uk/CG42. Accessed June 14, 2016.

32. Weinmann S, Roll S, Schwarzbach C, Vauth C, Willich SN. Effects of Ginkgo biloba in dementia: systematic review and meta-analysis. $B M C$ Geriatr. 2010;10:14.

33. Lott I, Doran E, Nguyen V, Tournay A, Head E, Gillen D. Down syndrome and dementia: a randomized, controlled trial of antioxidant supplementation. Am J Med Genet A. 2011;155A(8):1939-1948.

34. Imbimbo B, Solfrizzi V, Panza F. Are NSAIDs useful to treat Alzheimer's disease or mild cognitive impairment? Front Aging Neurosci. 2010;2:19.

35. Kalsy-Lillico S, Adams D, Oliver C. In: Emerson E, Hatton C, Dickson $\mathrm{K}$, Gone R, editors. Older Adults with Intellectual Disabilities: Issues in Ageing and Dementia. 2012.

36. Emerson E, Hatton C, Dickson K, Gone R, Caine A, Bromley J, editors. Clinical Psychology and People with Intellectual Disabilities. 2nd ed. Chichester: Wiley; 2012.

37. Lawlor BA. Behavioral and psychological symptoms in dementia: the role of atypical antipsychotics. J Clin Psychiatry. 2004;65(suppl 11):5-10.

38. Mantry D, Cooper SA, Smiley E, et al. The prevalence and incidence of mental ill-health in adults with Down syndrome. J Intellect Disabil Res. 2008;52(pt 2):141-155.

39. Wark S, Hussain R, Parmenter T. Down syndrome and dementia: is depression a confounder for accurate diagnosis and treatment? $J$ Intellect Disabil. 2014;18(4):305-314.

40. Tsiouris JA, Patti PJ, Flory MJ. Effects of antidepressants on longevity and dementia onset among adults with Down syndrome: a retrospective study. J Clin Psychiatry. 2014;75(7):731-737.

41. Lyketsos C, Sheppard J, Steele C, et al. A randomized placebocontrolled, double-blind, clinical trial of sertraline in the treatment of depression complicating Alzheimer's disease. Am J Psychiatry. 2000;157(10):1686-1689.

42. Prasher V. Practical Dementia Care for Adults with Down Syndrome or with Intellectual Disabilities. New York: Nova Sci; 2014.

43. Pueschel SM, Louis S, McKnight P. Seizure disorders in Down syndrome. Arch Neurol. 1991;48(3):318-320.

44. McCarron M, Gill M, McCallon P. Health co-morbidities in ageing persons with Down syndrome and Alzheimer's dementia. $J$ Intellect Disabil Res. 2005;49(Pt 7):560-566.

45. Lott IT, Doran E, Nguyem VQ, Tournay A, Movsesyan N, Gillen DL. Down syndrome and dementia: seizures and cognitive decline. $J$ Alzheimers Dis. 2012;29(1):177-185.

46. Prasher VP, Corbett JA. Onset of seizures as a poor indicator of longevity in people with Down syndrome and dementia. Int J Geriatr Psychiatry. 1993;8(11):922-927.

47. Mula M, Trimble MR. Antiepileptic drug-induced cognitive adverse effects: potential mechanisms and contributing factors. CNS Drugs. 2009;23(2):121-137.

48. British Psychological Society. Dementia and People with Intellectual Disabilities: Guidance on the Assessment, Diagnosis, Interventions and Support of People with Intellectual Disabilities Who Develop Dementia. Leicester: British Psychological Society; 2015.

49. Marshall M. How it helps to see dementia as a disability. J Dementia Care. 1998;6:15-17. 


\section{Publish your work in this journal}

Degenerative Neurological and Neuromuscular Disease is an international, peer-reviewed, open access journal focusing on research into degenerative neurological and neuromuscular disease, identification of therapeutic targets and the optimal use of preventative and integrated treatment interventions to achieve improved outcomes, enhanced survival and quality of life for the patient. The manuscript management system is completely online and includes a very quick and fair peer-review system. Visit http://www.dovepress.com/testimonials.php to read real quotes from published authors.

Submit your manuscript here: https://www.dovepress.com/degenerative-neurological-and-neuromuscular-disease-journal 